\title{
Letter regarding Lerch et al.: Bone remodelling around the Metha short stem in total hip arthroplasty: a prospective dual-energy $\mathrm{X}$-ray absorptiometry study
}

\author{
Owen Diamond • M. Gavan McAlinden
}

Received: 16 November 2011 / Accepted: 29 November 2011 /Published online: 17 December 2011

(C) Springer-Verlag 2011

\section{Dear Sir:}

I am writing in regard to the article by Lerch et al., an online-first publication from the 20th September 2011 issue entitled "Bone remodelling around the Metha short stem in total hip arthroplasty: a prospective dual-energy X-ray absorptiometry study" [1]. While carrying out a literature review on the use of the Metha stem we noticed that the ethical approval number for this paper "Ethic Committee No. 4226 " is registered on controlled-trails.com (Trial Reference Number ISRCTN54967983) by the same authors of the above mentioned paper as a controlled trial comparing two groups of 25 patients [2]. One group was to have the Metha short stem implanted and the control group was to have the Bicontact stem (AESCULAP AG, Tuttlingen, Germany) implanted with the primary outcome measure bone mineral density of the proximal femur around the stem using a DEXA scan at defined time points. On the ControlledTrials website it is stated that the Bicontact branch of the trial was ended after two years but that the Metha branch would continue for an additional two years. It would appear that the paper by Lerch et al. [1] is the analysis up to two years of the 25 patients who were implanted with the Metha stem but there is no data on the control group of 25 patients implanted with the Bicontact stem. If this trial was set up initially as suggested by the information on controlled-trials. com, as a direct comparison of the two stems, would it not be prudent to report the outcome of both stems and how they compared when publishing the results? Results of a direct comparison between the two types of stem would be of great interest to many surgeons.

Sincerely,

Mr Owen Diamond, MRCS DipSEM

Mr M. Gavan McAlinden, BSc MPhil FRCS (Tr \& Orth)

\section{References}

1. Lerch M, von der Haar-Tran A, Windhagen H, Behrens BA, Wefstaedt, P and Stukenborg-Colsman, CM (2011) Bone remodelling around the Metha short stem in total hip arthroplasty: a prospective dual-energy X-ray absorptiometry study. Int Orthop. 2011 Sep 21 [Epub ahead of print]

2. ISRCTN (2010) Periprosthetic bone mineral density (BMD) around two different stems in total hip arthroplasty. Available at: www.controlledtrials.com/isrctn/pf/54967983. Accessed 11 December 2011 